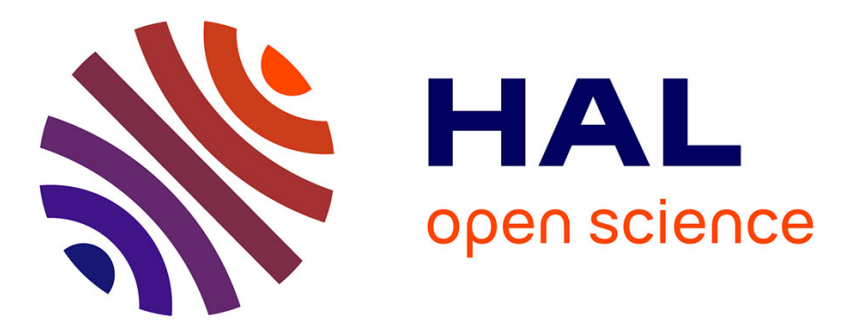

\title{
Robots for Inclusive Play: Co-designing an Educational Game With Visually Impaired and sighted Children
}

Oussama Metatla, Sandra Bardot, Clare Cullen, Marcos Serrano, Christophe Jouffrais

\section{- To cite this version:}

Oussama Metatla, Sandra Bardot, Clare Cullen, Marcos Serrano, Christophe Jouffrais. Robots for Inclusive Play: Co-designing an Educational Game With Visually Impaired and sighted Children. CHI '20: CHI Conference on Human Factors in Computing Systems, 2020, Honolulu, United States. pp.1-13, 10.1145/3313831.3376270 . hal-02926484

\section{HAL Id: hal-02926484 https://hal.science/hal-02926484}

Submitted on 21 Dec 2020

HAL is a multi-disciplinary open access archive for the deposit and dissemination of scientific research documents, whether they are published or not. The documents may come from teaching and research institutions in France or abroad, or from public or private research centers.
L'archive ouverte pluridisciplinaire HAL, est destinée au dépôt et à la diffusion de documents scientifiques de niveau recherche, publiés ou non, émanant des établissements d'enseignement et de recherche français ou étrangers, des laboratoires publics ou privés. 


\title{
Robots for Inclusive Play: Co-designing an Educational Game With Visually Impaired and Sighted Children
}

\author{
Oussama Metatla ${ }^{1}$, Sandra Bardot ${ }^{2}$, Clare Cullen ${ }^{1}$, Marcos Serrano ${ }^{2}$, Christophe Jouffrais ${ }^{2,3}$ \\ ${ }^{1}$ University of Bristol, ${ }^{2}$ University of Toulouse, ${ }^{3} \mathrm{CNRS}$ \\ \{o.metatla, c.cullen\}@ bristol.ac.uk, \{sandra.bardot, marcos.serrano, christophe.jouffrais\} @irit.fr
}

\begin{abstract}
Despite being included in mainstream schools, visually impaired children still face barriers to social engagement and participation. Games could potentially help, but games that cater for both visually impaired and sighted players are scarce. We used a co-design approach to design and evaluate a robotbased educational game that could be inclusive of both visually impaired and sighted children in the context of mainstream education. We ran a focus group discussion with visual impairment educators to understand barriers to inclusive play. And then a series of co-design workshops to engage visually impaired and sighted children and educators in learning about robot technology and exploring its potential to support inclusive play experiences. We present design guidelines and an evaluation workshop of a game prototype, demonstrating group dynamics conducive to collaborative learning experiences, including shared goal setting/execution, closely coupled division of labour, and interaction symmetry.
\end{abstract}

\section{Author Keywords}

Inclusion, Visual Impairment, Games, Education, Co-design

\section{CCS Concepts}

-Human-centered computing $\rightarrow$ Participatory design; Accessibility design and evaluation methods; •Applied computing $\rightarrow$ Collaborative learning;

\section{INTRODUCTION}

Visually impaired (VI) and blind children are increasingly educated in mainstream rather than special schools [42]. However, despite being included with their sighted peers, recent research identified persistent issues with participation $[51,56]$, reduced opportunities for collaborative learning and social engagement $[5,19]$ and potential for isolation [34]. These challenges are in part attributed to the structural and technical support that VI children receive in mainstream schools [34]. In particular, assistive learning technologies are often designed to be used by VI pupils alone and not by sighted peers, and can therefore reduce opportunities for inclusive learning experiences.

\footnotetext{
Permission to make digital or hard copies of all or part of this work for personal or classroom use is granted without fee provided that copies are not made or distributed for profit or commercial advantage and that copies bear this notice and the full citation on the first page. Copyrights for components of this work owned by others than the author(s) must be honored. Abstracting with credit is permitted. To copy otherwise, or republish, to post on servers or to redistribute to lists, requires prior specific permission and/or a fee. Request permissions from permissions@ acm.org.

CHI'20, April 25-30, 2020, Honolulu, HI, USA

(C) 2020 Copyright held by the owner/author(s). Publication rights licensed to ACM ISBN 978-1-4503-6708-0/20/04 .. \$15.00
}

DOI: https : //doi .org/10.1145/3313831.3376270

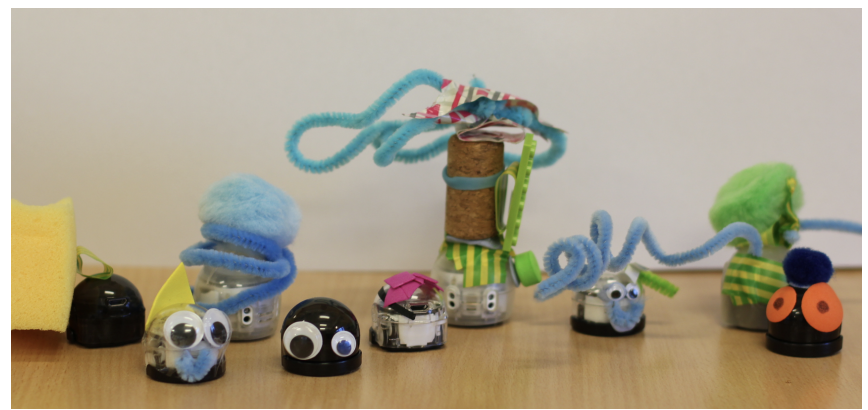

Figure 1. Customising Ozobots with anthropomorphic features and clothing items to allow for tactile identification and tracking.

Educational games could reduce barriers to inclusion. Games are effective means for learning [12] and, if designed with inclusion in mind, they can promote interactions that are equally engaging to both sighted and VI children [35]. However, accessible technologies, including accessible games, tend to focus on the needs of a specific target user group: for example those in need of accessibility support. This can work against objectives of inclusion since games that are designed to be accessible for VI players tend to be simplified to a point that makes them non-engaging to sighted players [48]. Meanwhile, games for sighted players are heavily visual, and therefore difficult to access for visually impaired players. In practice, this means games that can engage both visually impaired and sighted children are scarce. This raises a need to explore the design of technologies that promote inclusive play between disabled and non-disabled players in general, and poses a challenge for the design of inclusive educational games for disabled and non-disabled children in mainstream schools.

In this work, we explored how to support inclusive play experiences between children with and without visual impairments with the aim of promoting inclusive learning experiences in mainstream schools. In particular, we explored the extent to which off-the-shelf robotic devices, which are not designed with accessibility in mind, could be used to design an inclusive educational game. Additionally, we analysed the forms of inclusive play experiences that this may engender. We thus extend current work in this area by focusing on co-designing an inclusive educational game in a new context of interaction (mainstream schools), and with a mix of stakeholders (children with and without VIs and their educators). This characterises our approach as one that does not use the needs of a particular group as a starting point. We do this by addressing three key research questions: 1) What challenges and barriers are 
there to inclusive play experiences for visually impaired and sighted children in mainstream schools? 2) How can we codesign inclusive play technologies with participants who have mixed visual abilities? and 3) In what way does the resulting technology support inclusive play experiences?

To answer these questions, we conducted focus group discussions with experts in the education of visually impaired children to learn more about challenges and barriers to inclusive play experiences. We then ran co-design workshops with visually impaired and sighted children and their educators to learn about robot technologies and how these could be used to design an inclusive educational game. From these activities we derived a set of guidelines for the design of inclusive play experiences. We then recruited a group of game designers to develop a game concept using these guidelines, which we then developed into a prototype and evaluated in an inclusive school. We thus make the following contributions: 1) a characterisation of barriers to inclusive play in mainstream schools; 2) a demonstration of how engaging children and educators with mixed visual abilities through inclusive co-design activities enable joint production of radically new conceptions of technologies for inclusive play experiences; 3 ) an outline and discussion of a set of broad guidelines for inclusive play for disabled and non-disabled children.

\section{BACKGROUND}

\section{Inclusive Education Technologies}

Inclusive education grew out of a wave of school reforms to address the structural causes of inequalities between students needs, especially students with disabilities [53]. Inclusive education emphasises practices that allow pupils to experience and embrace diversity, including teaching approaches that enable learners to participate fully in a mainstream setting regardless of their needs [47]. In the UK, the move toward inclusive education was accompanied by an increase in the number of teaching assistants (TAs) working in mainstream schools [17, 44]. However, evidence from recent reviews suggests that TAs rarely receive the necessary support and training they need, and that this contributes to increasing provision and experiential challenges for pupils with additional support needs $[17,20]$. Children with VIs have complex needs that require appropriate provisions [3]. They have limited access to the curriculum via the visual medium, and accessing information via alternative mediums such as Braille, is often time-consuming or not possible [22]. A child with a severe VI is also likely to require additional support in developing social skills [43]. A number of researchers have developed novel accessibility and assistive technologies (ATs) that address such issues. Examples include, a portable note-taker to provide blind students with better access to classroom presentations [24], methods for auditory access to mathematical formulae [40], and rapid prototyping of learning materials using 3D printing [32].

Research on mixed-ability classrooms also shows increasing evidence that inclusive education technologies designed for both visually impaired and sighted children can alleviate some of the challenges associated with inclusive provisions. For instance, Thieme et al. developed an inclusive tool for collaborative coding [49], Freeman et al. explored the introduction of auditory beacons to support mobility and social engagement for visually impaired and sighted children [19], and Metatla et al. demonstrated support for engagement between children with mixed visual abilities through inclusive co-design techniques $[34,36]$ and voice-user interfaces [35]. Nonetheless, uptake of novel ATs in educational settings continues to be limited [7] due to a number of issues, including stigmatisation [46] and perceived usefulness [41]. Screen-reader and screen enlargement software and hardware continue to be the dominant ATs used by VI children in mainstream schools [32, 34]. This suggests that involving children with and without visual impairments as well as their educators in the design of inclusive educational technologies can improve uptake by ensuring designs are informed by and adequately embedded within ongoing practices and provisions.

\section{Inclusive Co-design}

Co-designing with and for visually impaired people has been explored across a range of domains. For example, to develop support for sensory motor rehabilitation of children with VIs [29], to co-design accessible toys [33], and multisensory educational technologies $[34,8]$. Research has also demonstrated that co-designing technology with children with special education needs (SEN) is valued for creating meaningful technology as well as for enriching and empowering children's experiences [18]. Many researchers are now actively seeking to involve children with SEN in the design of new educational technologies (e.g. [31, 55, 35, 14]). However, little research has explored inclusive co-design involving visually impaired and sighted children, and educators. Yet, this is particularly important when aiming to support inclusive education so that the context is more authentically understood $[6,34,14]$.

\section{Games for Visually Impaired Players}

Previous research has addressed the need to make games accessible for visually impaired players, either by adapting existing games $[4,54,48]$ or by creating new dedicated games [10, 38]. Research has particularly focused on adopting appropriate interaction modalities such as haptic or auditory feedback. For example, Blind Hero [54] replaces visual with haptic stimuli, in this case a glove with vibratory feedback, so that players know which buttons to press. RAD [48] is an accessible racing game that relies on sonification to represent the speed of the car and cues on the racetrack. Beyond appropriate interaction techniques, an adaptation or simplification of gameplay is necessary to make games accessible $[4,2]$. In an educational context, games can help children to learn and develop certain skills while playing $[10,38,50,52]$. For example, in Hungry Cat [10] VI children feed a cat by finding food in a room. This was shown to help children develop spatial mental maps. BraillePlay [38] helps players to learn Braille characters through a mobile game. Wilkerson et al. [52] designed a game to help blind children learn programming. However, these games are not designed to be played with sighted players.

\section{Robot Technologies for Visual Impairment}

Robot technology has recently shown promise to support nonvisual interaction with interfaces and displays. For instance, Guinness et al. developed the Haptic Video Player, which presents videos using mobile robots to allow for annotation by 
touching robots as they move over a touch screen [23]. Their results showed that many online videos can be improved by adding audio and tactile annotations, and that off-the-shelf hardware can be re-purposed to enable multimodal accessible video content. In the BotMap system, Ducasse et al. explored how blind users could use maps and execute zooming functions effectively while receiving tangible feedback through mobile robots [16]. We build on this work of re-purposing robot technology that is not necessarily designed with accessibility in mind to develop an educational game that address barriers to inclusive play experiences.

\section{FOCUS GROUP DISCUSSIONS}

We started our investigation by addressing the first research question: What challenges and barriers are there to inclusive play experiences for visually impaired and sighted children in mainstream schools? We held focus group discussions with two sets of experts. First, with qualified teachers of visual impairments (QTVIs) from the local authority's sensory support services. Five QTVIs participated in the first focus group discussion, which took place at the local offices. Each QTVI works with up to 20 families and with local schools to accompany the children through their education, to provide one-to-one teaching sessions, and to train staff. We held the second focus group discussion at a local inclusive school with three teaching assistants (TAs) and the school's special education needs coordinator (SENCo). The school is a community primary school covering ages 4 to 11 years. It has a dedicated special educational needs resource base for disabled children, including 5 visually impaired and blind children. Each child has a dedicated TA who assists them on a one-to-one basis. Discussions lasted around two hours. We presented our research objectives then asked questions about challenges and barriers to inclusive play in mainstream schools. We then let participants drive the discussions as they described their experiences. We recorded and transcribed the discussions. We used a thematic analysis where one researcher produced initial codes and labels of data segments, which we validated through peer validation [1], where two researchers met regularly to review and clarify coding and discuss themes.

\section{Challenges and Barriers to Inclusive Play Experiences}

\section{Engineering Social Engagement}

Participants acknowledged that visually impaired children, particularly those with severe VIs, often require additional support in developing and maintaining social engagement with peers. They mentioned that inclusive schools implement explicit mechanisms to help children nurture social skills through close TA supervision, and through social engineering schemes. TAs interact closely with the children and they form strong bonds. The roles of the TAs then involve not only adapting learning materials and providing assistance during lessons, but also supervising and regulating social encounters for children in the playground and during other social times. TAs pointed out a set of challenges that result from this close interaction; namely that they must balance supervision with allowing space for healthy social interactions: "children do an awful lot of looking out of the windows, kicking each other under the table, sniggering and giggling and all that, when the TA is there, they can't really be there as an adult and be seen to just ignore this" (TA3). Practically, this means that "non-curricular" social interaction is naturally reduced around TAs, and hence children with VIs miss out on: "a lot of learning that goes on with that [..] everything becomes mediated through adult behaviour, which actually isn't what [VI children] should be experiencing" (QTVI4).

Participants mentioned alternative mechanisms, designed to reduce dependence on adult supervision for social engagement. For instance, a "buddy system" where sighted peers are trained to "work with [VI children] each day, so [VI child] knows she has someone to play with while she makes her own friends" (SENCo). Another school uses a "friends bench" in the playground, reserved for children who are looking for someone to play with. This was mentioned as a good example of inclusive provision, because anyone could sit on the bench to look for a friend, not just disabled children. Despite these engineered mechanisms, participants pointed out that there was not enough support for inclusive play between children with mixed visual abilities. That is, once VI children do find sighted friends to play with or vice versa, there are not enough options engendering engaging play experiences available to them from that point forward.

\section{Computer Games Accessibility and Pace}

Computer games were mentioned as key for supporting engagement among peers. Participants discussed how accessible computer games provide an outlet for VI children and can be a way for them to engage in what they dubbed "healthy mischievous behaviour": "it's something for blind kids to be a little naughty, I caught him playing an audio game while wearing headphones when he was supposed to be using the calculator!" (TA4). But participants pointed out that the VIspecificity of these games could become a source of social isolation and frustration: "lots of kids talk about the computer games they're playing, but [VI children] completely missed out on that whole bit of social world" (QTVI2). One participant highlighted that: "computer games specifically designed for people with visual impairments are different from the sighted games and also a lot of them are quite adult." (QTVI4). There are thus barriers to inclusive play experiences related, on the one hand, to the accessibility of computer games and, on the other, to social interactions that occur around computer games.

Pace of computer games was highlighted as one of the significant barriers to making them truly accessible and engaging to both sighted and VI children: "say you're playing a game of snakes and ladders, and we've got tactile versions of that game, the pace to play it is very slow, so the [sighted] children are gonna get impatient especially young children" (TA3). In gauging their views on the characteristics of games that could be inclusive of both sighted and visually impaired children, participants highlighted examples that involve hands-on manipulation and more emphasis on spoken narration, speaking and listening: "one that works really well is [physical game's name] where you hold an object and you have to pull the right part according to spoken instructions, that one does work for everybody and [VI child] can keep up with the pace" (TA4). However, even then such games might not be appropriate for 
older children: "At seven you might get away with snakes and ladders, but by the age of 15 you're really not" (QTVI1).

\section{Physical Education Accessibility and Pace}

Physical education (PE) could be a natural place to develop hands-on engaging play experiences for VI and sighted children. But pace again posed a significant barrier to making PE and playground games inclusive of VI children, particularly when PE and playground activities involve team games: "if you're trying to be in a team game where you're the only one with a visual impairment then you can't keep up with the pace" (SENCo). A QTVI suggested that schools should be pushed through legislation to adopt more accessible physical games: "Goal ball is brilliant because it was devised for the visually impaired, it's quite slow paced, everyone is blindfolded, and everyone can play it at the same level" (QTVI1). But here too, participants mentioned potential issues with motivating sighted children to take on such games. Participants also discussed structural and organisational issues that could stand in the way of enforcing accessible and inclusive physical games in schools: "a lot of schools now fund specialist PE coaches to come, particularly in primary, some of those coaches are ready to take [VI child] into account, others don't, that's hard because the coaches are not members of the school staff so it becomes very tricky" (QTVI3).

\section{Independent Navigation and Mobility}

Mobility is a core part of physical play activities. Participants reflected on the way broader issues of independent mobility could accumulate to constitute barriers to social engagement and inclusive play. Learning how to move around the school was described as: "a massive learning curve" (QTVI3) for VI children, with significant time and effort required to reach independence: "they usually start by learning mobility routes a year before they even transfer [to a new school], and it can take a year to actually learn the routes around because we don't want them to be reliant on an adult for getting around as a guide" (SENCo). Most VI children receive mobility training from a dedicated mobility officer. Participants explained that there is no specific technological support for this process: "it's just the cane and touch and an instructor, the instructor sometimes makes Lego models to show where routes are on the school" (QTVI1). Because significant effort is invested in learning routes, VI children tend to stick to familiar routes, which can lead to reduced opportunities for more adventurous mobility that is key for serendipitous social encounters. Some of these issues depend on the personality of the child in question: "we have some children who are very bold and confident and just go for it, others are terrified and just stay in their safe base, and that's an issue" (TA2). However, here too, there seemed to be a tension between the general aim of reducing adult supervision and maintaining a safe environment for the children: "because he's taking his cane out into the play ground, obviously there is a safety issue with that, so there is always an adult there with him. Usually I go out at play time, I try not to stay with him, but you kind of have to just check that he's alright" (TA3). Thus, a combined concern for hazardous encounters and social isolation means that the potential for dependency on adult supervision increases, especially at social times, e.g. between lessons and during play time.
Table 1. Workshops Children Participants Details.

\begin{tabular}{|c|c|c|c|c|}
\hline Pseudonyms & Gender & Age & Visual Impairment & Attendance \\
\hline Caroline & F & 10 & Sighted & All \\
Cian & M & 9 & Sighted & All \\
Laila & F & 10 & Blind & 1,3 and 4 \\
Meryem & F & 10 & Sighted & All \\
Peter & M & 9 & Blind & All \\
Richard & M & 10 & Visually impaired & All \\
Romeo & M & 9 & Visually impaired & 1,2 and 3 \\
Tom & M & 10 & Visually impaired & 1,2 and 4 \\
\hline
\end{tabular}

\section{CO-DESIGN WORKSHOPS}

We next ran co-design workshops to generate insights about how to design an inclusive educational game that could address some of the barriers outlined above. We aimed to address the second research question: How can we co-design inclusive play technologies with participants who have mixed visual abilities? We worked with eight children (five male, 9-10 years, 5 VI, and 3 sighted "buddies") and six adults (all female, 4 TAs, and 1 SENCo). Due to other commitments, some children only attended some of workshops (Table 1).

\section{Workshop Procedure}

We ran four co-design workshops on school premises during normal school days. They lasted two hours each, two to three weeks apart. Each workshop had a set of learning objectives and a set of design objectives. Together these introduced design directions that gradually evolved to realise the broader aim of generating insights about the design of a robot-based inclusive educational game. All workshops had the same structure: an introduction, a set of design activities, then a showcase and discussion, mimicking typical lesson structures at the school. The introduction and showcase/discussion involved all participants. In the design activities, participants worked in groups of four children and one to two TAs. The SENCo and some of the TAs tended to move between groups. We provided the TAs with activity sheets to help facilitate the design activities. Two researchers ran the sessions and codesigned with participants. A third researcher took notes and kept time. Sessions were also video recorded. We obtained written consent from parents, TAs and the SENCo, and verbal assent from the children. This procedure was approved by the Ethics Board at the authors' institution.

We used off-the-shelf Ozobots (www. ozobot. com) because they are an educational robotic product targeting the age range of our child participants and have already been successfully used on systems for VI people $[23,16]$. They are designed to be engaging to sighted children, and so have potential to address some of the barriers identified in the focus group discussions. Ozobots Bit are small $(2.5 \mathrm{~cm}$ diameter $x 2.5 \mathrm{~cm}$ high, 9 grams), have two wheels and a color sensor. Users can control their movement by two means: using coloured line drawings (e.g. the robot will follow a line underneath it, color codes speed), and using a visual programming language. They have an approximate autonomy of $1 \mathrm{~h}$ when moving.

\section{Workshop 1: Introducing the Robots}

As a learning objective, we aimed, in the first workshop, to help participants understand what constitutes a robot technology and to learn about the basic functionality of Ozobots. As 


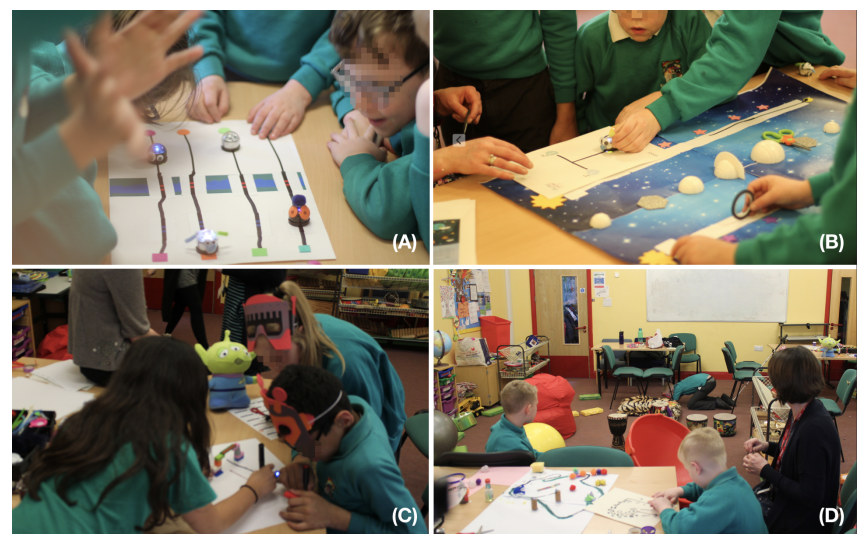

Figure 2. (A) Children applying coloured line codes to program robots' speed in a basic robot racing game. (B) In Workshop 2, participants played a space game where robots traverse the solar system and answer trivia questions about planets. (C, D) In Workshop 4, participants built a physical obstacle course in the classroom, a map to represent it and used robot navigation to provide each other with instructions on how to traverse the classroom in real-time.

a design objective, we wanted participants to reflect on the extent to which Ozobots are accessible to VI children and to design solutions to accessibility issues that they may identify. We combined a variety of activities to achieve these objectives, including listening to various robot audio recordings to generate discussions and reflections, handling Ozobots (four robots per group), and low-fi multisensory crafting using a variant of the multisensory box of stuff [34].

Outcomes: Audio recordings of robot sounds were effective in getting the children to articulate and share their own understanding of what constitutes a robot and to think about different forms robots could take, their tasks and where they might be found. All Participants became familiar with switching Ozobots on and off and with the way they followed lines. Participants discovered three accessibility issues: identifying and differentiating between robots, accessing on/off buttons and line drawings, and following the robots as they moved. To address these issues, participants used multisensory crafts to customise their robots with anthropomorphic features and clothing items (Fig. 1). E.g. Romeo clothed his robot in a woolly hat, Laila added sticky toffee scent on top of a sponge hat, and Tom found it difficult to locate the on/off button, so he augmented it with a rubber button. Robots could then be differentiated by the way they felt and smelled, crafts could be used as tactile trackers, allowing children to follow robots' movement by lightly placing a hand on top as it moved. For line drawings accessibility, some children used scented pens and craft threads to augment and replicate drawn lines. But a TA discovered that tactile tape was the most effective means for making robot paths accessible; they were easier to craft, trace and, unlike threads, preserve Ozobots mobile functionality.

\section{Workshop 2: Coding Robots and Initial Game Concepts}

We next introduced participants to more advanced movement control of the Ozobots. Because the visual programming language is inaccessible to visually impaired people, we focused on using coloured line drawings, and we engaged participants in learning about controlling speed (slow/fast) and direction (right/left) of the robots. In terms of design objectives, we aimed to engage participants in thinking about practical applications for coding robots through two basic games; a racing game where they race their robots to traverse a path at different speeds; and a space game where they control the movements and directions of their robots across the solar system and answer trivia about different planets (Fig. 2 (B)). We chose "space" as a theme because TAs suggested it matched children's ongoing curricular activities at the school.

Outcomes: Participants coded robots' movements using a combination of coloured pens and colour-coded labels. They worked in pairs to race their robots, demonstrating understanding of the codes explored in the workshop. They enjoyed the competitive nature of the games and demonstrated curriculum knowledge in the space game. Using colours to code the robots remained inaccessible for the VI children, however, particularly for Peter and Laila, who had the most severe visual impairments in the group and who had to rely on the assistance of TAs and sighted buddies to get engaged in the coding process. The children enjoyed the collaborative coding process despite this. And although there was no focus on learning outcomes in the workshop, the TAs commended the embedding of learning objectives about space, which they used as an opportunity to connect workshop activities to subject matters relevant to the game, including history and design technology.

\section{Workshop 3: Computational Thinking, Maps \& Games}

Having learned about the basic functionalities and coding of robots in the first two workshops, the aim of the third workshop was to introduce participants to algorithms and computational thinking, and because of the issues highlighted in the focus group discussion around joint action, to develop their joint map-making design skills using crafts, codes and objects. We used role play, fiction and Lo-Fi crafting. Participants created and impersonated their own robot characters, they wore robot masks and chose a name, sound effect, and a function/superpower for their robot character (Fig. 2 (C)). They then worked in groups to break down a familiar task (e.g. making a pizza or a smoothie) into a set of basic instructions, and acted as robots to receive and execute these instructions for completing the tasks. Next, participants designed a basic game concept: to design a rescue map and a set of instructions to guide a robot towards rescuing a stranded alien.

Outcomes: Participants created robot characters incorporating multisensory features (e.g. sound, textures and scent) and functions (e.g. a flying robot). The use of a familiar task was effective in helping children think about how to breakdown a complex task into basic tasks and devise instructions, and role playing was effective in getting the children to observe the importance of order and precision when executing each others instructions. For example, Richard discovered that, as a robot, he needed to both narrate what he was doing to give feedback to those giving him instructions, and to compliment those narrations with multisensory effects (e.g. mouthing sounds, stomping feet) to help visually impaired peers. Children enjoyed using multisensory craft materials to create maps for their game concept. Maps had Lego bricks as bridges, tactile and scented materials to represent obstacles (e.g. the scent of 
the sea for sharks), tactile tape for routes and borders. We encountered technical problems with robots batteries not lasting as long as the workshops, despite fully charging them. We thus created a "charging station" that children took control of.

\section{Workshop 4: Physical Courses}

We aimed to build on the participants' positive engagement with role playing, map design and generating and executing navigation instructions. The fourth workshop focused on exploring how participants could learn to apply these skills in the design of a collective physical game about accessible navigation, and to complement this with opportunities to learn more about team coordination. This workshop theme also ties back to the issues of independent physical mobility and social interaction that were highlighted in the focus group discussions. Participants worked in groups to design a physical obstacle course inside a classroom using a range of objects, e.g. sports equipment, furniture, cushions and musical instruments. In groups, they designed a map of the obstacle course, and then swapped roles. One pair read the map using an Ozobot character to generate navigation instructions. The other executed the instructions to traverse the obstacle course.

Outcomes: Participants used a variety of items to construct their course, e.g. musical instruments to solve riddles, and chairs to create tunnels. The TAs helped the children iterate their designs by using a white cane to trial the accessibility of the course, and children modified the course in response to TA feedback; for example Laila and Caroline suggested hanging bells on chairs to make directions more obvious. In general, the children enjoyed the physical navigation component of the game, and were all effective at generating and executing instructions and at traversing the course. With one of the groups, we started to notice that Tom was finding it difficult to keep track of map details. The complexity of the course, items on the map and the pace at which Cian was traversing the course made it difficult to read the map and generate instructions in real-time. There were thus some issues with the complexity of the objects used to populate maps, which led to joint thinking between researchers and TAs about managing map content for different groups of children. The TA in this case sketched a simplified version of the map and printed it using swell paper, and then modulated Cian's pace to match Tom's map reading speed. This helped Tom read the map and generate instructions more effectively (Fig. 2 (D)).

\section{Inclusive Educational Game Design Guidelines}

Six high level guidelines emerged from a high level analysis of workshop data, including debriefing notes validated through discussions and references to video data:

1. Incorporate multisensory feedback to equalise access and meaning making: Given the mixed visual abilities that were present, multisensory materials and feedback were key to engage all participants in equally meaningful ways.

2. Include elements of crafting to promote joint action and ownership of game content: Using crafting to customise robots and design maps was an important and engaging element of the workshops that both children and educators enjoyed. Often crafting activities went on for much longer than planned and the children took pride in showcasing the creations.

3. Distribute and share roles between players to widen perspectives and promote empathy: Giving all children the opportunity to take on and swap roles provided a means for shared reflection and engaged discussions.

4. Use narration to moderate pace: Using narration to guide design activities, describe non-verbal actions and share instructions was important to maintain a common pace for everyone. Narration was also seen as a key component for making games more inclusive.

5. Combine physical navigation and maps to increase engagement and joint action: The children enjoyed both building and traversing the obstacle course. Creating maps and sharing instructions provided a means for focused and engaged coordination and learning.

6. Embed learning objectives to match interests and promote teacher control: Workshop activities were designed to be engaging and to encourage creativity. Embedding learning objective was also important for the educators, providing them with a means for maintaining control and regulation.

\section{GAME DEVELOPMENT AND EVALUATION}

We then worked with professional game designers to design a game concept using the guidelines. Eight people working in games' accessibility for visually impaired people participated in the workshop lasting 80 minutes. designers were people working in the design of accessible games at one of the authors' institution. They have experience mainly in interactive board games (e.g. with tangibles, cards) with some of these games targeted at children. We adopted the six-to-one method [28]; generating six ideas and then developing one. After an introduction, each participant had 10 minutes to generate six ideas for the game. Then everyone presented their ideas for criticism. This led to the proposal of a refined game concept.

Game plot and structure: An alien robot species wants to take over the solar system and has kidnapped some of the planets. Using an Ozobot as the protagonist, players are required to travel through the solar system to check which planets have been kidnapped and to rescue them. To prevent the alien species from kidnapping further planets, players must reach them and correctly answer questions about them. The game had three interwoven parts: 1) moving robots on a Planet Board (Fig. 3 (A)) to "travel across space" and trigger questions about the planetary system. All children planned and crafted robot routes in this part; 2) exploring a Lego Navigation Map (Fig. 3 (B)) of the school to locate missing planets. Here children swapped roles: navigators read the map and generate instructions, rangers use the instructions to go and retrieve the planet; and 3) going into the school to locate and retrieve the planets (Fig.3 (C)).

\section{Evaluation Workshop}

We ran an evaluation workshop to examine the third research question: In what way does the developed prototype support inclusive play experiences? Three TAs and seven children who also took part in previous workshops participated in the 

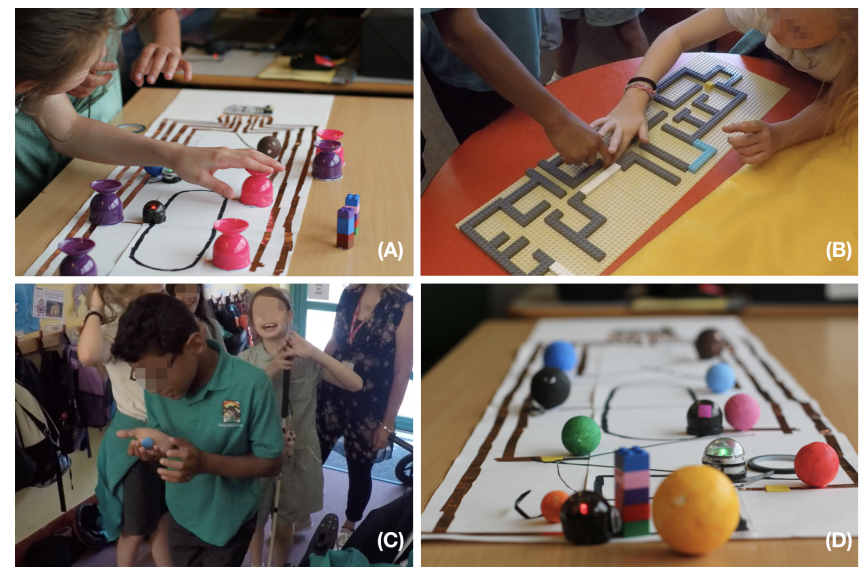

Figure 3. The developed game: (A) the Planet Board where Ozobots travel from one planet to another; (B) a Lego Navigation Map to locate kidnapped planets; (C) which must retrieved from somewhere in the school; (D) completed board with all planets saved.

evaluation (Romeo could not attend). They were split into two groups (four/three children and two/one TAs in each group) and played the game from start to finish, lasting between 30 and 40 minutes. One TA played the role of a planet kidnapper, instructed on where to go to hide kidnapped planets. One researcher played the role of the game narrator, guiding the children through play. Another researcher observed play, took notes and kept time.

Data Collection \& Analysis: We video recorded the sessions and collected feedback from participants and conducted a thematic analysis. We used a similar analysis process as before, with the exception of combining inductive and deductive coding, focusing on behaviours indicative of collaborative learning and participation. This is because these were seen as particularly problematic for visually impaired and sighted children in the focus group discussions and in prior work (e.g. [5]). Additionally, collaborative learning is characterised by behaviours we were interested to explore. Namely, social processes regulating interactions among a small group of participants as they work together to complete a problem-solving task designed to promote engagement and learning [26]. The deductive coding was based on Dillenbourg's characterisation of collaborative learning [15] in terms of: shared goals; interaction symmetry, and division of labour.

\section{Outcomes}

Five themes emerged from the above process: 1) negotiating and executing shared goals; 2) symmetry of actions and knowledge including TA control as a means for restoring symmetry; 3) peripheral learning opportunities and forms of explicit and implicit learning 4) levels of division of labour; and 5) Map-to-World and World-to-Map Transfers.

\section{Negotiating and Executing Shared Goals}

Children and TAs engaged in processes of jointly planning and negotiating the execution of shared goals. This included higher levels goals, e.g. rescuing a planet, as well as lower level goals involving breaking down a challenge into smaller tasks and solving them together. An example of the latter is shown in the excerpt below. Here, the children were deciding how to use tactile tape to draw a path for the robot:

\footnotetext{
Peter: can I have the tape there please [draws an imaginary line with his index finger]

Caroline: yeah [cuts tape] I'm just going to cut that bit off

Peter: is it too long?

Meryem: [points to same area] yeh, measure it on there and then leave an extra bit, maybe we can put it on later
}

Their exchange also shows how sighted children took care to include the VI child in the execution of this goal, which is a further goal they independently took upon themselves:

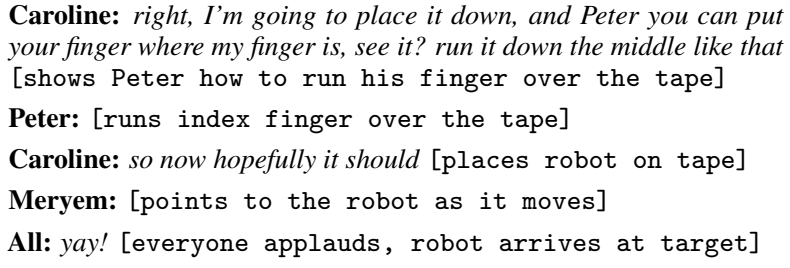

Caroline: right, I'm going to place it down, and Peter you can put your finger where my finger is, see it? run it down the middle like that [shows Peter how to run his finger over the tape]

Peter: [runs index finger over the tape]

Caroline: so now hopefully it should [places robot on tape]

Meryem: [points to the robot as it moves]

All: yay! [everyone applauds, robot arrives at target]

\section{Symmetry of Actions, Knowledge and TA Control}

Unlike the example above, however, there were instances where sighted children were less inclined to include their VI co-player in their joint planning and execution of shared goals. This then created an asymmetry in the group's locus of attention and action. In an example of this, Cian and Richard were deciding on how to outmaneuver an antagonist robot, Peter (who has a much more severe VI than Richard) remained focused on the protagonist robot's functionality, which was irrelevant to the immediate focus of the children's goal:

\footnotetext{
Narrator: 11 points, for 10 points I will grant you a flick action to flick it off the board, for 5 points I will grant you a blocking wall

Cian: shall we just go around it

Richard: yup

Peter: ahh, it's not working [lifts robot up and shakes it]

Richard: actually no

Cian: why? let's go around it

Peter: [feels the previous tactile path] is it working now?

Cian: then we don't have to use any points

Richard: $\mathrm{erm}$ [picks up the tactile tape]

Peter: [places the robot on the previous part of the tactile route] it's going, it's going

Richard: [attempts to place the tape where Peter's hands are] Peter, excuse me
}

Cian and Richard's actions and those of Peter are clearly asymmetrical and misaligned here. Often, it was at points similar to the one shown above that we observed explicit interventions from the TAs to restore symmetry:
TA: Cian, tell Peter what you are doing
Cian: it's fine
Peter: right [holds on the robot]
TA: Peter let Cian help
Cian: we need to save our points for that one [points to a faster moving antagonist]
Peter: [lets robot go, tracks movement with his hand, lifts a cup] Ifound a planet! [double taps the planet]

System: Jupiter is the biggest planet in the solar system, true or false? Peter, Cian, Richard: [shout at the same time] true! 
As a form of knowledge symmetry, we observed instances where the children used the Q\&A component of the game to engage in conversation that realigns their beliefs about each other's knowledge. For example, by reflecting on common experiences from other lessons, e.g.: "oh I know this! remember when we did planet research, I did all the planets and how many moons they have, but I can't remember" (Meryem); neither can I! (Laila).

\section{Peripheral Learning Opportunities}

There were instances where other parts of the game seem to afford other means for engaging in aligning knowledge symmetry, mainly by creating opportunities for peripheral learning and informal peer instruction. An example of this is shown in the excerpt below in which Caroline helps Tom with a conceptual framing, which was then re-enforced by the TA. Here, Tom, Caroline and a TA are walking back through the school corridor after retrieving a kidnapped planet:

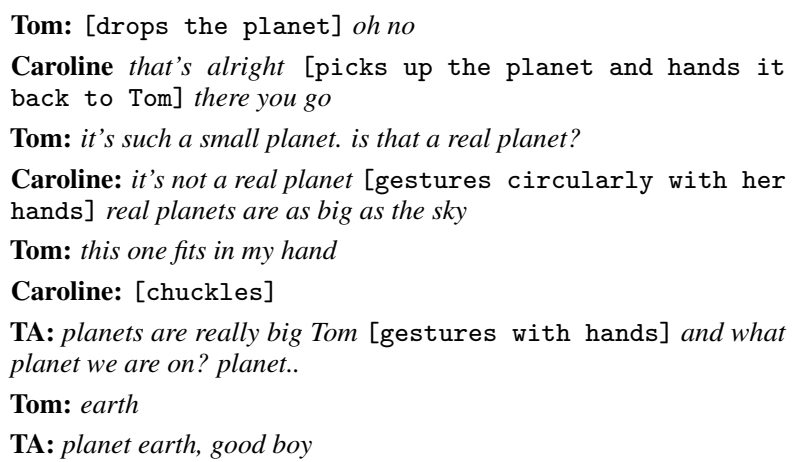

\section{Levels of Division of Labour}

We observed two levels of division of labour during game play, which occurred mostly on the Planet Board. In earlier parts of the game, division of labour centred around crafting and was driven by the sighted players who gave explicit instructions to their VI co-players, e.g.:

\footnotetext{
Meryem: where are we? where is the Ozobot? it's here by the black planet, alright, so you find where the next bit is and I prepare the tape Laila: [traces finger from current position and locates the next destination]

Meryem: ok, I will now run the tape and you run your finger on it [places tape] ready?

Laila: yeh, there [runs finger across the tape]
}

There were fewer exchanges of explicit instructions from sighted children to regulate division of labour in later parts of the game. Tasks became implicitly divided and closely coupled, with symmetrical and smooth coordination of related actions. Here is an example of such seemless labour division:

Cian: let's do the final one

Richard: yes! We can go over [over the antagonist robot path]

Peter: [holds the two cups that designate the starting and target points]

Cian: [prepares the tactile tape and places it down near Peter's left hand] this should be easy enough then Richard: right, ready? [holds other end to launch robot] Cian: wait I need to put more tape down

Peter: let me [grabs robot and positions it on the tape with left hand, keeps right hand on destination cup]
Cian: [finishes taping the path] wait does this [the antagonist robot] stay blocked?

Richard: yes, yes, yes

Peter: [follows robot by with left hand on top unti] it reaches destination, shouts:] we found it!

Peter, Cian: [lift cup together and reveal the planet]

It is important to note that both explicit and implicit levels of labour division centred around crafting and engaged both sighted and VI children. This suggests that crafting, as captured by our design guidelines, was indeed an important game element to incorporate, providing a means for joint locus of attention and opportunities for group regulations of play.

\section{Map-to-World and World-to-Map Transfers}

We observed moments in play where children transferred actions and knowledge performed or obtained from one part of the game onto another. We noted two types of transfer mechanisms in particular: transfers of non-verbal guiding actions; and transfers of terminology to disambiguate navigation instructions. These transfers occurred between the game boards and the school environment, and vice versa. The following two excerpts show an example of transferring a non-verbal guiding action from the Navigation Map to the school corridor. Here Meryem uses tapping sounds to guide Laila:

\footnotetext{
Meryem: the front of the school is here [places Laila's hands at one end of the map] can you find the yellow block?

Laila: yellow block? [feels around with her hand]

Meryem: it's on this huge [map] so it's not jut going to be where you are now [referring to where Laila has her hand]

Laila: That's the front of the school [feels with her hand]

Meryem:[moves her hand near the location of the yellow block and taps continuously on the table] it's closer to where I'm tapping, you'll find it around there

Laila: oooh [moves hands and face toward the sound, finds Meryem's hand] there it is
}

The inclination to augment the environment with a guiding sound appeared again when the same pair was walking through the corridor. The tapping action was replaced with clapping, but was used for a similar purpose; i.e. to use sound to guide Laila towards a particular location. Here, Laila and Meryem are walking back through the corridor having retrieved a kidnapped planet. Tom and Caroline run towards them:

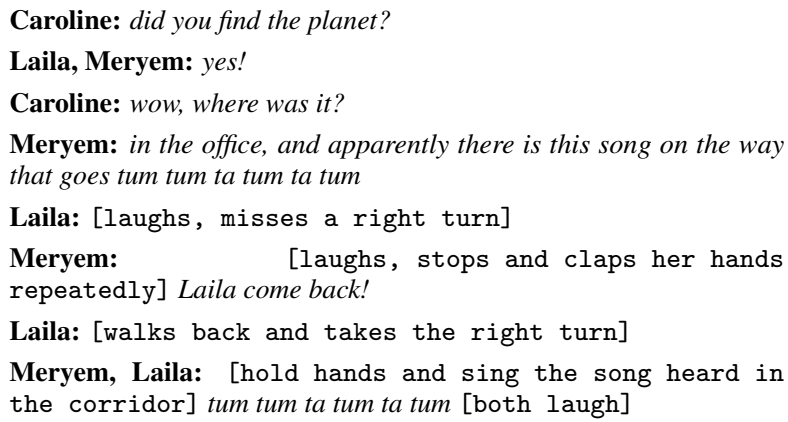

The second type of transfers took a different form. In this case, it was the terminology used to refer to landmarks and to formulate navigational instructions that was transferred from the Lego map to the corridor and vice versa, e.g.: "we're coming up to what he thought was the resource room, so now we have 
to turn right" (Cian). This was thus an explicit transfer of terminology across both environments and player roles, i.e. a space ranger explicitly adopts the same terminology to interpret navigation instructions in the real-world environment as generated on the map by the navigator. In the following example, we see a world-to-map terminology transfer, used to resolve misinterpretation when reading the map:

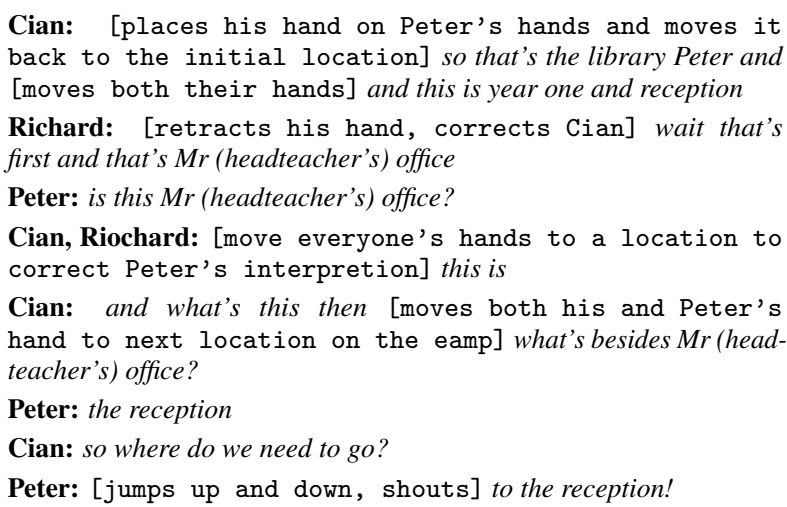

We thus observed an aptitude to use maps effectively, to appropriate modes of reading maps, and to apply navigation instructions in the real world. These aptitudes manifest equally in the game play by both visually impaired and sighted children.

\section{DISCUSSION}

Approaches to the design of accessible games have tended to focus on the specific functional needs of a target disability user group. This can work against the objectives of promoting inclusive play between disabled and non-disabled players. We examined how we could address this challenge in the context of designing an educational game inclusive of both visually impaired and sighted children. We aimed to alleviate some of the challenges and barriers which visually impaired children meet in mainstream schools: around inclusive learning experiences, social engagement and participation.

Discussions with education experts highlighted the need to support visually impaired children in developing and maintaining social engagement with their peers. We found that focus on functional accessibility could impede social engagement, and inclusive play as a vehicle for it, for example via over-dependence on teaching assistants. We observed that this gap manifests as a set of disconnects between VI and non VI children, around pace and stimulation, across computer and physical games: disconnects which also map onto broader issues of independent mobility inside schools. This led us to explore the use of robotic technology with basic mobility functions as a basis for designing inclusive play experiences.

\section{Inclusive Co-design Approach}

Building on work on inclusive co-design [39, 35], we aimed to emphasise inclusion, both in terms of the design process and its outcomes. We achieved this by bringing together children with and without visual impairments, alongside their educators, in a series of activities that provided opportunities for learning about a robot technology, and about design, accessibility and inclusion. An important starting point was our decision to choose a technology which did not accentuate the needs of a particular user group over another. The particular robots we used helped in this regards. They are designed to engage sighted children, but they have also been shown to provide functional accessibility to visually impaired adult users $[23,16]$. The workshops were thus an opportunity to learn not just about robotic technology, but also about the ways in which children with different visual abilities engage with, and through, such a technology.

Our co-design approach was characterised by several important elements: 1) we engaged participants with a mixed set of visual abilities (visually impaired and sighted), age groups (children, adults), and roles (pupils, teaching assistants and designers), thus extending prior work that emphasised the importance of including teachers of visual impairments in design (e.g.[45, 21]). 2) We organised the workshops within school premises, and modelled their structure to mimic typical lessons familiar to the children, which provided a comfortable and familiar environment. 3) We embedded learning objectives so that children could both learn about the technology being explored, and learn, through it, a subject matter (eg. space). 4) We shared facilitation roles with the educators, who were present as both participants and supporters of the sessions, as recommended by prior work in this area [34]. 5) We used a blend of design methods, including multisensory materials, role play and narration, based on insights from the focus group discussions, and prior work on how to create a design space that is equally engaging to all participants [18].

\section{How Inclusive Play Experiences Were Nurtured}

The focus groups and co-design workshops yielded a set of design guidelines for inclusive educational mobility games. The game used Multisensory Feedback in the form of tangible interactions and auditory feedback. Audio rendered the questions in the game while tangible hands-on interactions supported engagement and maintained a pace that was comfortable for all players. For example, hiding planets on the board created an equal sense of anticipation, reducing asymmetry between players' ability to overview the full play experience. The benefits of multisensory feedback that we observed are consistent with findings from prior work (e.g. [9, 49, 30, 14]). Crafting was a crucial component, both helping children organise and coordinate their work, and providing an opportunity for them to learn how to be inclusive of each other, in terms of action and pace. For example, we saw how crafting helped children share and negotiate goals and move to more seamless and inclusive division of labour. This engaged, collaborative, and inclusive behaviour was also re-enforced by the guideline to Distribute and Share Roles between Players, because it provided children with an opportunity to experience challenges in play from various perspectives and to tailor their approach to support each other accordingly. Finally, the use of Narration was also crucial in ensuring the pace of play was comfortable and engaging for all players. Pace was a recurring concern, appearing in the focus group discussions, co-design activities, and final evaluation. Spoken narration, targeting a common modality of interaction provided anchor points to regulate the pace of play when needed. This was particularly important to help visually impaired children keep track of play, but also to help sighted children maintain engagement and interest. 


\section{Withdrawing Robots}

Combining Physical Navigation and Maps was an important element to include in a mobility-centered game. In their feedback, children unanimously singled out going out into the school to locate kidnapped planets as their favourite part of the game. The robots did not figure at all in their feedback about the play experience. This was unexpected, contrasting to the design workshops where we observed children's attachment to the robots (e.g. creating customised characters and asking to work with their own robots in each workshop, and in Tom's case, always physically holding on to his robot). It is therefore interesting that once embedded in a physical game, the robot technology withdrew and was no longer the focus of engagement between the children. In considering the shift from functional accessibility to inclusive interaction, the above observation points to a novel use of robot technology for accessible interaction, which contrasts prior work involving these specific types of robot $[16,23]$, and in which the technology remained in the foreground of accessible interaction.

\section{Physical Navigation and Spatial Cognition}

During play, children combined and appropriated different modes of map reading and applied navigation instructions effectively in the real world. The most striking manifestation of these aptitudes was in the way children transferred navigation actions and knowledge across the static and mobile aspects of the game. These observations confirm existing results about transfer of spatial knowledge between maps and real setting for visually impaired adults and children [27]. For example, following an audio-based game play of building explorations, young people with visual impairments constructed accurate mental representations of the building [13]. Our findings also confirm exploratory approaches to supporting blind navigation through embedded multisensory feedback [19, 34, 25, 11], and point to the potential of using games of this sort to design inclusive technologies for blind collaborative navigation. As a starting point, we envision further studies to characterise a design space that leverages and supports the various types of transfers that helped the children maintain efficiency and engagement during collaborative spatial navigation. In our case, these included different action transfers e.g. guiding actions and terminology, occurring across navigation environments (static and mobile) and across roles (rangers and navigators).

\section{Broader implications on Inclusive Education}

A further design guideline that emerged from the workshops is the importance of embedding learning objectives. While this might seem trivial for educational games, we note that the design process and final play experience it produced afforded four layers of learning: Firstly, play experiences should allow children to engage in content-based learning, e.g. to learn about a particular subject matter like space. Secondly, to engage critically with technical aspects of the gaming material. In our case this was the accompanying computational thinking and its application to generating and executing navigation instructions. Thirdly, children should be engaged in design thinking, for example crafting customisation, designing physical courses and maps. Finally, and most importantly, they should learn about inclusion itself, how to consider each others needs, abilities, concerns and perspectives. Engaging with peers in this way provides an opportunity to demystify misconception about disabilities, e.g. showing that there are methods to explore the world other than relying on vision. This is thus an important dimension of learning that inclusive educational games in schools should aim to target. Inclusive educational games then can leverage the advantage of inclusive schools to nurture a space for sighted children to learn about disabilities. This expands on the concept of inclusive education beyond children working together to achieve equal learning outcomes [37]. Educational experiences, and play as a vehicle for that, should provide visually impaired children with an opportunity to lead in how visual impairment is shared with other people.

\section{LIMITATIONS \& FUTURE WORK}

We evaluated the game with the same children who contributed to its design. The co-design workshops produced high level guidelines, and so the resulting game concept and mechanics were in effect novel to the children involved. There is also value in involving the children designers in the final evaluation, particularly for an inclusive design approach: The children expected to see a full game at the end of the process, it was important to fulfil this expectation, and evaluating it also meant that the children not only experienced the game they took part in designing, but were also empowered in gaining a sense of ownership over the resulting technology. Despite this, future work should also include other children in order to provide further validation for the design guidelines. Furthermore, the focus of the evaluation was on improving inclusion in terms of learning experience rather than knowledge acquisition, and in this sense was limited by not measuring learning outcomes. Future work should also evaluate learning outcomes.

\section{CONCLUSION}

We used a co-design approach to design and evaluate an robotbased educational game that is inclusive of both visually impaired and sighted children. Our work addresses the challenge of shifting design emphasis from functional accessibility to inclusion, in order to cater for both disabled and non-disabled children in the context of inclusive mainstream education. We presented a set of co-design explorations that helped us generated a set of design guidelines for inclusive play experiences, using robot technology for spatial navigation and mobility. Our guidelines emphasise multisensory feedback, hands-on creation, and narration as a means for modulating pace and stimulation; all of which were highlighted as potential barriers to inclusive interactions. Our evaluation demonstrated how emphasis on inclusive experience led to a gradual withdrawal of the robot technology to the background of the experience. It also highlighted the importance of considering complex layers of learning when designing inclusive educational games for visually impaired and sighted children.

\section{ACKNOWLEDGEMENTS}

We would to thank all the participating school and support services, educators, children and parents, and acknowledge the support of EPSRC Fellowship Grant EP/N00616X/2 Crossmodal Interactive Tools for Inclusive Learning project, and AccessiMap ANR-14-CE17-0018 


\section{REFERENCES}

[1] Mohammed Ibrahim Alhojailan. 2012. Thematic analysis: A critical review of its process and evaluation. West East Journal of Social Sciences 1, 1 (2012), 39-47.

[2] Ronny Andrade, Melissa J Rogerson, Jenny Waycott, Steven Baker, and Frank Vetere. 2019. Playing Blind: Revealing the World of Gamers with Visual Impairment. In Proceedings of the 2019 CHI Conference on Human Factors in Computing Systems. ACM, 116.

[3] Christine Arter. 2013. Children with visual impairment in mainstream settings. Routledge.

[4] Matthew T. Atkinson, Sabahattin Gucukoglu, Colin H. C. Machin, and Adrian E. Lawrence. 2006. Making the Mainstream Accessible: Redefining the Game. In Proceedings of the 2006 ACM SIGGRAPH Symposium on Videogames (Sandbox '06). ACM, New York, NY, USA, 21-28. DOI :

http://dx.doi.org/10.1145/1183316.1183321

[5] Julie A Bardin and Sandra Lewis. 2008. A survey of the academic engagement of students with visual impairments in general education classes. Journal of Visual Impairment \& Blindness 102, 8 (2008), 472.

[6] Laura Benton and Hilary Johnson. 2015. Widening participation in technology design: A review of the involvement of children with special educational needs and disabilities. International Journal of Child-Computer Interaction 3 (2015), 23-40.

[7] Emily C Bouck. 2016. A National Snapshot of Assistive Technology for Students With Disabilities. J. Special Education Technology 31, 1 (2016), 4-13.

[8] Emeline Brulé and Gilles Bailly. 2018. Taking into Account Sensory Knowledge: The case of geo-techologies for children with visual impairments. In Proceedings of the 2018 CHI Conference on Human Factors in Computing Systems. ACM, 236.

[9] Emeline Brule, Gilles Bailly, Anke Brock, Frédéric Valentin, Grégoire Denis, and Christophe Jouffrais. 2016. MapSense: multi-sensory interactive maps for children living with visual impairments. In Proceedings of the 2016 CHI Conference on Human Factors in Computing Systems. ACM, 445-457.

[10] Carmen Chai, Bee Lau, and Zheng Pan. 2019. Hungry Cat-A Serious Game for Conveying Spatial Information to the Visually Impaired. Multimodal Technologies and Interaction 3 (02 2019), 12. DOI : http://dx.doi .org/10.3390/mti3010012

[11] Ling Chen, Ibrar Hussain, Ri Chen, WeiKai Huang, and Gencai Chen. 2013. BlueView: a perception assistant system for the visually impaired. In Proceedings of the 2013 ACM conference on Pervasive and ubiquitous computing adjunct publication. ACM, 143-146.

[12] Cynthia Chiong and Carly Shuler. 2010. Learning: Is there an app for that. In Investigations of young children's usage and learning with mobile devices and apps. New York: The Joan Ganz Cooney Center at Sesame Workshop. 13-20.
[13] Erin Connors, Elizabeth Chrastil, Jaimie Sanchez, and Lotfi B Merabet. 2014. Action video game play and transfer of navigation and spatial cognition skills in adolescents who are blind. Frontiers in human neuroscience 8 (2014), 133.

[14] Clare Cullen and Oussama Metatla. 2019. Co-designing Inclusive Multisensory Story Mapping with Children with Mixed Visual Abilities. In Proceedings of the 18th ACM International Conference on Interaction Design and Children. ACM, 361-373.

[15] Pierre Dillenbourg. 1999. What do you mean by collaborative learning? P. Dillenbourg (Ed) Collaborative-learning: Cognitive and Computational Approaches (1999), 1-19. http://infoscience.epfl.ch/record/33765

[16] Julie Ducasse, Marc Macé, Bernard Oriola, and Christophe Jouffrais. 2018. BotMap: Non-Visual Panning and Zooming with an Actuated Tabletop Tangible Interface. ACM Transactions on Computer-Human Interaction (TOCHI) 25, 4 (2018), 24.

[17] Peter Farrell, Alison Alborz, Andy Howes, and Diana Pearson. 2010. The impact of teaching assistants on improving pupils' academic achievement in mainstream schools: A review of the literature. Educational Review 62, 4 (2010), 435-448.

[18] Christopher Frauenberger, Julia Makhaeva, and Katharina Spiel. 2017. Blending Methods: Developing Participatory Design Sessions for Autistic Children. In Proceedings of the 2017 Conference on Interaction Design and Children. ACM, 39-49.

[19] Euan Freeman, Graham Wilson, Stephen Brewster, Gabriel Baud-Bovy, Charlotte Magnusson, and Hector Caltenco. 2017. Audible Beacons and Wearables in Schools: Helping Young Visually Impaired Children Play and Move Independently. In Proceedings of the 2017 CHI Conference on Human Factors in Computing Systems. ACM, 4146-4157.

[20] Michael F. Giangreco. 2013. Teacher assistant supports in inclusive schools: Research, practices and alternatives. Australasian Journal of Special Education 37, 2 (2013), 93-106.

[21] Stéphanie Giraud, Philippe Truillet, Véronique Gaildrat, and Christophe Jouffrais. 2017. "DIY" Prototyping of Teaching Materials for Visually Impaired Children: Usage and Satisfaction of Professionals. In International Conference on Universal Access in Human-Computer Interaction. Springer, 515-524.

[22] J Greaney, M Tobin, and E Hill. 1999. Braille Version of the Neale Analysis of Reading Abilities. RNIB (1999).

[23] Darren Guinness, Annika Muehlbradt, Daniel Szafir, and Shaun K Kane. 2018. The Haptic Video Player: Using Mobile Robots to Create Tangible Video Annotations. In Proceedings of the 2018 ACM International Conference on Interactive Surfaces and Spaces. ACM, 203-211. 
[24] David S Hayden, Liqing Zhou, Michael J Astrauskas, and John A Black Jr. 2010. Note-taker 2.0: the next step toward enabling students who are legally blind to take notes in class. In Proc. 12th int. ACM SIGACCESS conf. ACM, 131-138.

[25] Florian Heller and Johannes Schöning. 2018. NavigaTone: Seamlessly Embedding Navigation Cues in Mobile Music Listening. In Proceedings of the 2018 CHI Conference on Human Factors in Computing Systems. ACM, 637.

[26] David W Johnson and Roger T Johnson. 1987. Learning together and alone: Cooperative, competitive, and individualistic learning. Prentice-Hall, Inc.

[27] Orly Lahav and David Mioduser. 2008. Haptic-feedback support for cognitive mapping of unknown spaces by people who are blind. International Journal of Human-Computer Studies 66, 1 (2008), 23-35.

[28] Carine Lallemand and Guillaume Gronier. 2015. Méthodes de design UX: 30 méthodes fondamentales pour concevoir et évaluer les systèmes interactifs. Editions Eyrolles.

[29] Charlotte Magnusson, Héctor Caltenco, Sara Finocchietti, Giulia Cappagli, Graham Wilson, and Monica Gori. 2015. What do you like? early design explorations of sound and haptic preferences. In Proceedings of the 17th International Conference on Human-Computer Interaction with Mobile Devices and Services Adjunct. ACM, 766-773.

[30] Charlotte Magnusson, Per-Olof Hedvall, and Héctor Caltenco. 2018. Co-designing together with Persons with Visual Impairments. In Mobility of Visually Impaired People. Springer, 411-434.

[31] Laura Malinverni, Joan Mora-Guiard, Vanesa Padillo, MariaAngeles Mairena, Amaia Hervás, and Narcis Pares. 2014. Participatory design strategies to enhance the creative contribution of children with special needs. In Proceedings of the 2014 conference on Interaction design and children. ACM, 85-94.

[32] Samantha McDonald, Joshua Dutterer, Ali Abdolrahmani, Shaun K Kane, and Amy Hurst. 2014. Tactile aids for visually impaired graphical design education. In Proc. 16th int. ACM SIGACCESS conf. ACM, 275-276.

[33] Joanne McElligott and Lieselotte Van Leeuwen. 2004. Designing sound tools and toys for blind and visually impaired children. In Proceedings of the 2004 conference on Interaction design and children: building a community. ACM, 65-72.

[34] Oussama Metatla and Clare Cullen. 2018. "Bursting the Assistance Bubble": Designing Inclusive Technology with Children with Mixed Visual Abilities. In Proceedings of the 2018 CHI Conference on Human Factors in Computing Systems. ACM, 346.
[35] Oussama Metatla, Alison Oldfield, Taimur Ahmed, Antonis Vafeas, and Sunny Miglani. 2019. Voice User Interfaces in Schools: Co-designing for Inclusion With Visually-Impaired and Sighted Pupils. In Proceedings of the 2019 CHI Conference on Human Factors in Computing Systems. ACM, 378.

[36] Oussama Metatla, Marcos Serrano, Christophe Jouffrais, Anja Thieme, Shaun Kane, Stacy Branham, Émeline Brulé, and Cynthia L Bennett. 2018. Inclusive education technologies: Emerging opportunities for people with visual impairments. In Extended Abstracts of the 2018 CHI Conference on Human Factors in Computing Systems. ACM, W13.

[37] Oussama Metatla, Anja Thieme, Emeline Brulé, Cynthia L Bennett, Marcos Serrano, and Christophe Jouffrais. 2019. Toward classroom experiences inclusive of students with disabilities. interactions 26, 1 (2019), $40-45$.

[38] Lauren R. Milne, Cynthia L. Bennett, Richard E. Ladner, and Shiri Azenkot. 2014. BraillePlay: Educational Smartphone Games for Blind Children. In Proceedings of the 16th International ACM SIGACCESS Conference on Computers \& Accessibility (ASSETS'14). ACM, New York, NY, USA, 137-144. DOI : http://dx.doi.org/10.1145/2661334.2661377

[39] Cecily Morrison, Nicolas Villar, Anja Thieme, Zahra Ashktorab, Eloise Taysom, Oscar Salandin, Daniel Cletheroe, Greg Saul, Alan F Blackwell, Darren Edge, and others. 2018. Torino: A tangible programming language inclusive of children with visual disabilities. Human-Computer Interaction (2018), 1-49.

[40] Emma Murphy, Enda Bates, and Dónal Fitzpatrick. 2010. Designing auditory cues to enhance spoken mathematics for visually impaired users. In Proc. 12th int. ACM SIGACCESS conf. ACM, 75-82.

[41] Chang S Nam, Sangwoo Bahn, and Raney Lee. 2013. Acceptance of assistive technology by special education teachers: A structural equation model approach. International Journal of Human-Computer Interaction 29, 5 (2013), 365-377.

[42] RNIB. 2013. Key statistics on the prevalence and population of children and young people with vision impairment. (2013).

[43] Joao Roe. 2008. Social inclusion: meeting the socio-emotional needs of children with vision needs. British J. Visual Impairment 26, 2 (2008), 147-158.

[44] U Sharma and SJ Salend. 2016. Teaching Assistants in Inclusive Classrooms: A Systematic Analysis of the International Research. Australian Journal of Teacher Education 41, 8 (2016), 118-134.

[45] Lei Shi, Holly Lawson, Zhuohao Zhang, and Shiri Azenkot. 2019. Designing Interactive 3D Printed Models with Teachers of the Visually Impaired. In Proceedings of the 2019 CHI Conference on Human Factors in Computing Systems. ACM, 197. 
[46] C Sik-Lányi and others. 2015. Barriers and facilitators to uptake of assistive technologies: summary of a literature exploration. Assistive Technology: Building Bridges 217 (2015), 350.

[47] Miriam D Skjørten. 2001. Towards inclusion and enrichment. Education Special Needs Education: An Introduction. Oslo: Unipub Forlag (2001).

[48] Brian A Smith and Shree K Nayar. 2018. The RAD: making racing games equivalently accessible to people who are blind. In Proceedings of the $2018 \mathrm{CHI}$ conference on human factors in computing systems. ACM, 516.

[49] Anja Thieme, Cecily Morrison, Nicolas Villar, Martin Grayson, and Siân Lindley. 2017. Enabling Collaboration in Learning Computer Programing Inclusive of Children with Vision Impairments. In Proceedings of the 2017 Conference on Designing Interactive Systems. ACM, 739-752.

[50] M. I. Torres-Carazo, M. J. Rodríguez-Fórtiz, and M. V. Hurtado. 2016. Analysis and review of apps and serious games on mobile devices intended for people with visual impairment. In 2016 IEEE International Conference on Serious Games and Applications for Health (SeGAH). 1-8. DOI :

http://dx.doi.org/10.1109/SeGAH. 2016.7586263

[51] Giacomo Vivanti, Ed Duncan, Geraldine Dawson, and Sally J Rogers. 2017. Facilitating Learning Through Peer Interactions and Social Participation. In
Implementing the Group-Based Early Start Denver Model for Preschoolers with Autism. Springer, 87-99.

[52] Matt Wilkerson, Amanda Koenig, and James Daniel. 2010. Does a Sonar System Make a Blind Maze Navigation Computer Game More "Fun"?. In Proceedings of the 12th International ACM SIGACCESS Conference on Computers and Accessibility (ASSETS '10). ACM, New York, NY, USA, 309-310. DOI : http://dx.doi.org/10.1145/1878803.1878886

[53] Margret A Winzer. 2000. Special education in the 21st century: Issues of inclusion and reform. Gallaudet University Press.

[54] Bei Yuan and Eelke Folmer. 2008. Blind Hero: Enabling Guitar Hero for the Visually Impaired. In Proceedings of the 10th International ACM SIGACCESS Conference on Computers and Accessibility (Assets '08). ACM, New York, NY, USA, 169-176. DOI : http://dx.doi.org/10.1145/1414471.1414503

[55] Ru Zarin and Daniel Fallman. 2011. Through the troll forest: exploring tabletop interaction design for children with special cognitive needs. In Proceedings of the SIGCHI Conference on Human Factors in Computing Systems. ACM, 3319-3322.

[56] Li Zhou, Amy T Parker, Derrick W Smith, and Nora Griffin-Shirley. 2011. Assistive technology for students with visual impairments: Challenges and needs in teachers' preparation programs and practice. J. Visual Impairment \& Blindness 105, 4 (2011), 197. 